\title{
MARCO CIVIL DA INTERNET: ANÁLISE DAS DECISÕES JUDICIAIS QUE SUSPENDERAM O APLICATIVO WHATSAPP NO BRASIL - 2015-16
}

\section{MARCO CIVIL DA INTERNET: ANALYSIS OF JUDICIAL DECISIONS THAT SUSPEND THE WHATSAPP APPLICATION IN BRAZIL- 2015-16}

\author{
${ }^{1}$ Irineu Francisco Barreto Junior \\ ${ }^{2}$ Marco Antonio Lima
}

\section{RESUMO}

Este artigo analisa decisões judiciais que suspenderam o funcionamento do aplicativo Whatsapp no Brasil, em 2015 e 2016. O Marco Civil da Internet, além de trazer princípios amplamente conhecidos para o segmento digital, introduz um novo fundamento voltado a algo extremamente sensível dentro da rede de computadores, o registro, guarda e armazenagem do conteúdo das aplicações e dos provedores da rede. A problemática abordada neste estudo trata da fundamentação das sentenças judiciais que suspenderam o aplicativo e a metodologia aplicada na pesquisa foi a revisão crítica da legislação aplicável e da doutrina até então formulada sobre o Marco Civil.

Palavras Chave: Sociedade da Informação; Whatsapp; Marco Civil da Internet.

\begin{abstract}
This paper analyzes the judicial decisions that suspended the operation of the Whatsapp application in Brazil, between 2015 and 2016. The Marco Civil da Internet and bring widely known principles to the digital segment, introduces a new principle aimed at something extremely sensitive within the network computers, registration and storage of the content of applications and network providers. The issues addressed in this study addresses the legal basis of court rulings that suspended the application and the methodology used in the research was a critical review of the applicable law and doctrine until then formulated on the Brazil web legislation.
\end{abstract}

Keywords: Information Society; Whatsapp; Brazilian Internet Law.

\footnotetext{
${ }^{1}$ Doutor em Ciências Sociais pela Pontifícia Universidade Católica - PUC, São Paulo, (Brasil). Docente do Programa de Mestrado em Direito da Sociedade da Informação da Faculdades Metropolitanas Unidas - FMU, São Paulo, Brasil. Analista de Pesquisas da Fundação Seade, São Paulo. E-mail: ifbjunio@ seade.gov.br ${ }^{2}$ Mestre em Direito da Sociedade da Informação pela Faculdades Metropolitanas Unidas - FMU, São Paulo, (Brasil). Especialista em Direito das Relações de Consumo pela Pontifícia Universidade Católica - PUC, São Paulo. Professor do Curso de Direito da FMU-SP. Advogado. E-mail: marcoantoniolima1 @ terra.com.br
} 


\section{INTRODUÇÃO}

Este artigo analisa o Marco Civil da Internet (REPÚBLICA FEDERATIVA DO BRASIL. Lei 12.965/14), legislação que estabelece princípios, garantias, direitos e deveres para a utilização da Internet no Brasil, com foco específico nas decisões judiciais que suspenderam o funcionamento do aplicativo Whatsapp no Brasil, entre 2015 e 2016. O Marco Civil, além de trazer fundamentos amplamente conhecidos para o segmento digital, introduz um novo princípio voltado a algo extremamente sensível dentro da rede de computadores, o registro, guarda e armazenagem do conteúdo das aplicações e dos provedores da rede. Além desses aspectos, a lei de 2014 fornece as diretrizes para atuação do Poder Público quando das ações para inclusão digital e educação para o uso da Rede Mundial de Computadores, trouxe o embasamento normativo para tratar dos casos que versem sobre a Internet e Tecnologia da Informação, procurando cobrir lacuna legal sobre aspectos econômicos, comportamentais e tecnológicos no ambiente da rede mundial de computadores. (JESUS, 2014, p. 17)

A revolução tecnológica ocorrida nos meios de comunicação deu origem a uma nova era denominada como Sociedade da Informação. A sua principal característica é a facilidade de obtenção de informações advindas de qualquer lugar do mundo em tempo quase que real, de forma jamais vista na história da humanidade. Denota-se que a informação é o centro gravitacional desta nova era, em outras palavras, é possível afirmar que ela possui valor comercial. Barreto Júnior (2015, p. 410) ao tratar do tema esclarece que:

\footnotetext{
O advento do Informacionalismo é, indubitavelmente, a principal marca econômica da sociedade em rede. Reorganiza a produção de riqueza no sistema econômico, no qual há uma gradativa valoração da informação como mercadoria e fator de geração de valor econômico, o que torna a National Association of Securities Dealers Automated Quotations (Nasdaq), bolsa de valores das empresas tecnológicas, tão estratégica, em termos de organização econômica, quanto a tradicional New York Stock Exchange, denominada bolsa de Wall Street. As megacorporações informativas (Google, Facebook e Yahoo, entre outras) acumulam vestígios de informações sobre os usuários da Internet, tais como seus padrões de navegação, compras realizadas on-line, preferências culturais, religiosas e ideológicas, websites de interesse, verbetes e expressões pesquisadas nos websites de busca, entre outras, "impressões digitais eletrônicas" que servem para estabelecer uma categorização minuciosa de cada usuário na rede. (...). Circunscreve-se no fato de que há inúmeros usos para esses perfis eletrônicos, tal como direcionamento de publicidade on-line, oferta de mercadorias relacionadas ao perfil do consumidor, além de montar cadastros de valor incomensurável sobre os cidadãos da sociedade em rede. (BARRETO JUNIOR (2015, p. 410)
} 
A problemática abordada neste estudo aborda a fundamentação legal das sentenças judiciais que suspenderam o aplicativo Whatsapp, no período anteriormente citado. Para tal finalidade, a metodologia aplicada é a revisão crítica da legislação aplicável e da doutrina até então formulada sobre o Marco Civil da Internet e a guarda de registros de comunicações e uso de aplicações dos usuários da rede mundial de computadores.

\section{ANÁliSE DAS AÇÕES JUDICIAIS QUE AUTORIZARAM O BLOQUEIO DO WHATSAPP NO BRASIL}

O provedor de aplicações da Internet Whatsapp da empresa Facebook foi bloqueado pela Justiça pela primeira vez em 25 de fevereiro do ano 2015, em cumprimento a um mandado judicial expedido no dia 11 daquele mesmo mês. Naquela oportunidade, o juiz Luiz Moura, da Central de Inquéritos da Comarca de Teresina, possivelmente pautado no Marco Civil da Internet (BRASIL, 2014) determinou a suspensão temporária, em todo o Brasil, dos serviços de referido aplicativo. Destacamos que o trâmite deste processo está resguardado pela proteção legal do Segredo de Justiça (art. 93, IX, CF [BRASIL, 1988]), contudo, de acordo com a Secretaria de Segurança do Estado do Piauí a ordem judicial teve em sua origem o descumprimento de decisões judiciais que determinavam a retirada de circulação de imagens de crianças e adolescentes expostas sexualmente no aplicativo de mensagens instantâneas (DECISÃO DE JUIZ DO PIAUÍ..., 2015). Ainda assim, a decisão não foi cumprida, pois na mesma data o Egrégio Tribunal de Justiça do Estado do Piauí, em decisão liminar proferida pelo Desembargador Raimundo Nonato da Costa Alencar, derrubou referida decisão, sob o argumento de que:

\footnotetext{
A fim de melhor ilustrar a falta de proporcionalidade que mana do ato questionado, imagine-se um juiz que, insatisfeito com a contumácia de determina empresa telefônica em prestar-lhe informações sigilosas, determine a suspensão, em todo o território nacional, dessa modalidade serviço de comunicação. $\mathrm{Ou}$, em uma analogia mais rústica, determinasse esse juiz a interrupção da entrega de cartas e encomendas pelo correio, apenas baseado na suspeita de que, por exemplo, traficantes estariam fazendo transitar drogas por esse meio. (BRASIL, 2015a)
}

Em 16 de dezembro do mesmo ano, outra decisão judicial determinou a suspensão dos serviços de mensagens instantâneas do aplicativo Whatsapp da empresa Facebook, pelo prazo de 48 horas em todo o Brasil. Referida ordem foi emanada pela Juíza Sandra Regina Nostre Marques, da 1. ${ }^{\mathrm{a}}$ Vara Criminal de São Bernardo do Campo, como medida de apoio 
para tornar efetiva a ordem judicial não atendida no dia 23 de julho de 2015, reiterada no dia 07 de agosto do mesmo ano, em processo criminal que tramita em segredo de justiça, em que um suspeito é investigado por crimes de latrocínio, tráfico de drogas e associação à organização criminosa denominada Primeiro Comando da Capital (PCC). A decisão foi proferida após pedido do Ministério Público que fundamentou o seu pedido no Marco Civil da Internet (BRASIL, 2014). A suspensão teve início às 0h do dia 17 e durou aproximadamente 12h, pois, na mesma data, foi suspensa pelo Egrégio Tribunal de Justiça do Estado de São Paulo, em decisão liminar, proferida pelo Desembargador Relator Xavier de Souza, da $11^{\mathrm{a}}$ Câmara Criminal, que invocou a desproporcionalidade da medida, conforme trecho do julgado abaixo transcrito:

Sob este aspecto, em face dos princípios constitucionais, não se mostra razoável que milhões de usuários sejam afetados em decorrência da inércia da impetrante, mormente quando não esgotados outros meios disponíveis para a obtenção do resultado desejado.

Cita a magistrada que foi imposta multa coercitiva, sem sucesso, daí a adoção da medida extrema.

Mas é possível, sempre respeitada a convicção da autoridade apontada como coatora, a elevação do valor da multa a patamar suficiente para inibir eventual resistência da impetrante, solução que, aparentemente, não foi adotada na origem. (BRASIL, 2015b)

A terceira ordem judicial determinando a suspensão dos serviços do aplicativo Whatsapp, em todo o território nacional, ocorreu em 02 de maio de 2016, por força do mandado exarado pelo juiz de direito Marcel Maia Montalvão, da Vara Criminal de Lagarto, em Sergipe, que, em processo criminal que tramita em segredo de justiça, determinou a interrupção dos serviços pelo prazo de $72 \mathrm{~h}$., com início às $14 \mathrm{~h}$, daquele mesmo dia. Este mesmo magistrado já havia determinado, em outro processo, a prisão do argentino Diego Dzoran, vice-presidente da empresa Facebook na América Latina, por descumprimento das decisões que determinavam a apresentação do conteúdo das mensagens instantâneas trocadas pelos investigados por tráfico de drogas e crime organizado, pelo aplicativo Whatsapp.

A prisão ocorreu no dia $1^{\circ}$ de março de 2016, sendo que no dia seguinte o Tribunal de Justiça local, considerou ilegal a prisão e determinou a cessação da coação. Com relação à decisão que determinou a interrupção nos serviços, o Desembargador Relator Cezário Siqueira Neto, do Egrégio Tribunal de Justiça de Sergipe, ao analisar o recurso da empresa Facebook, em seu plantão noturno, houve por bem negar o deferimento ao pedido liminar de efeito suspensivo ativo, mantendo a decisão de primeira instância, sob o argumento de que "a alegação dada pelo Facebook, de que deve resguardar a privacidade de seus usuários, serve só para encobrir interesses patrimoniais da empresa." Porém, na mesma data, a empresa 
apresentou o sucedâneo recursal correspondente ao "Pedido de Reconsideração", que foi analisado pelo Desembargador Relator Ricardo Múcio Santana de Abreu Lima, e conseguiu a liminar para suspender os efeitos da decisão monocrática, o conteúdo da decisão, contudo, é desconhecido em razão do sigilo decorrente do segredo de justiça, reconhecido, também, em grau recursal.

Com relação a esta terceira ordem de suspensão, é de todo oportuno destacar que o Juiz Federal Ali Mazloum, da $7^{\text {a }}$ Vara Criminal de São Paulo, encaminhou à ANATEL ordem para o desbloqueio do aplicativo WhatsApp na linha utilizada por aquela Seção Judiciária, ressaltando a importância do uso da tecnologia da informação para o bom desenvolvimento das atividades daquele cartório. A curiosidade é que para atender àquela determinação a ANATEL deveria estabelecer a possibilidade de comunicação daquela Vara com quaisquer linhas que tenha interesse em se comunicar, sob pena de multa, conforme trecho abaixo transcrito:

Requisite-se do presidente da Anatel que determine às operadoras de telefonia o imediato restabelecimento dos serviços de WhatsApp para a linha utilizada por esta Vara, permitindo-se a expedição e recepção de mensagens com quaisquer linhas que queiram ou necessitem com ela se comunicar. Assim qualquer usuário deve ter livre acesso à referida linha. (BATE-PAPO LIBERADO..., 2016).

Apenas dois meses após, em 19 de julho de 2016, nova decisão judicial determinou a interrupção dos serviços do WhatsApp, em todo o território nacional. A decisão foi lavrada pela Juíza Daniela Barbosa Assunção de Souza, da 2. ${ }^{a}$ Vara Criminal de Duque de Caxias, no Estado do Rio de Janeiro. De acordo com a magistrada a empresa Facebook (dona do aplicativo WhatsApp) descumpriu as ordens judiciais para interceptação das mensagens de suspeitos de práticas criminosas, antes mesmo que fossem criptografadas, contudo, a empresa em resposta apresentada em inglês disse que não arquiva ou copia as mensagens compartilhadas entre os seus usuários. Desta forma, segundo a magistrada, a empresa não só desrespeita o nosso ordenamento jurídico como, também, despreza o próprio poder judiciário. Argumentou a magistrada que, a desabilitação da chave de criptografia com a interceptação das mensagens, não geraria qualquer ofensa à privacidade dos usuários, pois seria restrita a determinados usuários e devidamente fundamentada. A imprensa ofereceu destaque a essa decisão:

A decisão de uma juíza de Duque de Caxias (RJ) que provocou o bloqueio do WhatsApp no Brasil por cinco horas nesta terça-feira (19) abriu uma nova frente para as autoridades que tentam forçar os donos do aplicativo de mensagens a colaborar com investigações criminais no país. O serviço, que tem cerca de 100 milhões de usuários no país, foi liberado no início da noite pelo presidente do STF (Supremo 
Tribunal Federal), Ricardo Lewandowski, que considerou o bloqueio desproporcional.

Em vez de pedir o conteúdo de conversas ou a identidade de usuários, como ocorreu nos casos anteriores, a juíza Daniela Barbosa de Souza determinou que o WhatsApp desabilite a criptografia que garante o sigilo das mensagens e permita o monitoramento das conversas de suspeitos em tempo real pelos investigadores.

A decisão atendeu a um pedido da $62^{\mathrm{a}}$ Delegacia de Polícia Civil, que investiga uma organização criminosa em Duque de Caxias. A juíza já havia enviado três ofícios ao Facebook, dono do aplicativo, para que a ordem fosse cumprida. Mas a empresa se negou a atender à determinação, e foi por isso que a juíza mandou bloquear o serviço.

Nos casos anteriores, o WhatsApp argumentou que não tinha como fornecer o conteúdo das conversas e outras informações porque não as armazena em seus servidores. Recentemente, o aplicativo adotou um sistema de criptografia mais forte, que embaralha o conteúdo das mensagens e só permite que os participantes de cada conversa tenham acesso a ele. (JORNAL FOLHA DE SÃO PAULO, 20 de julho de 2016)

$\mathrm{Na}$ análise da juíza Daniela Barbosa Assumpção de Souza, "o aplicativo tornou-se ferramenta de criminosos por limitar as possibilidades de rastreá-los. " $\mathrm{Na}$ opinião da magistrada "é comum a interceptação telefônica flagrar um suspeito dizer ao outro para tratarem determinado assunto no WhatsApp, porque sabem que no aplicativo ficam impunes", afirmou para a reportagem do jornal Folha de São Paulo. "Estou acostumada com reforma de decisões, isso faz parte da magistratura. Mas a gente lamenta algumas vezes, sobretudo quando fortalece uma empresa que descumpre decisões judiciais reiteradamente. Isso desautoriza muito a primeira instância e dá mais força para quem descumpre a lei", disse a juíza. Segundo ela, "mesmo antes da reversão do bloqueio, a investigação já estava prejudicada, porque os policiais continuam sem acesso às informações e, agora, os criminosos sabem que há uma apuração em andamento. (JORNAL FOLHA DE SÃO PAULO, 19 de julho de 2016)

Ocorre que, em razão da decisão do Juiz da Vara Criminal de Lagarto, correspondente a terceira ordem de bloqueio do aplicativo em maio de 2016, o Partido Popular Socialista - PPS arguiu, perante o Supremo Tribunal Federal, o descumprimento de preceito fundamental com pedido de tutela cautelar, para impedir novas interrupções. A liminar foi deferida pelo Ministro Ricardo Lewandowski, que considerou que a decisão ofende o direito fundamental à liberdade de expressão e de manifestação, sendo desproporcional, afetando a sociedade como um todo:

Como se verifica, o direito de livre expressão e comunicação mereceu destaque do Poder Constituinte originário, com status, inclusive, de cláusula pétrea, ou seja, não pode ser abolido sequer por emenda constitucional.

Na sociedade moderna, a internet é, sem dúvida, o mais popular e abrangente dos meios de comunicação, objeto de diversos estudos acadêmicos pela importância que 
tem como instrumento democrático de acesso à informação e difusão de dados de toda a natureza.

$[\ldots]$

Ora, a suspensão do serviço do aplicativo WhatsApp, que permite a troca de mensagens instantâneas pela rede mundial de computadores, da forma abrangente como foi determinada, parece-me violar o preceito fundamental da liberdade de expressão aqui indicado, bem como a legislação de regência sobre o tema. Ademais, a extensão do bloqueio a todo o território nacional, afigura-se, quando menos, medida desproporcional ao motivo que lhe deu causa. (BRASIL, 2016)

Os sucessivos bloqueios do WhatsApp não são ações isoladas. Conforme matéria publicada pelo ABRAJI (Associação Brasileira de Jornalismo Investigativo), "cerca de três em cada quatro processos movidos por políticos contra empresas de mídia pedindo retirada de notícias, comentários ou outras informações do ar são direcionados a duas redes sociais: Facebook e Twitter. " A ABRAJI fundamenta-se na da base de dados do projeto Ctrl+X, projeto por ela desenvolvido, que mapeia, desde as eleições de 2014, as ações judiciais de candidatos e partidos para cercear a publicação de informações sobre eles.

O projeto agora contabiliza mais de 1.200 ações na justiça eleitoral. $\mathrm{O}$ alvo mais frequente desse tipo de pedido de retirada de conteúdo é o Facebook, réu em 865 $(71,5 \%)$ dos processos catalogados. Já o Twitter, terceiro mais acionado na Justiça, é réu em 2,5\% das ações. A segunda empresa mais visada com ações para remoção de conteúdo é o Google, citado em 191 (15,8\%) das ações. Os dados continuarão a ser atualizados regularmente para as eleições de 2016 e podem ser acessados de maneira interativa na página ctrlx.org.br.

Ainda segundo a ABRAJI, "seu banco de dados tem cadastradas ações judiciais contra meios de comunicação que datam desde 2002. " Os períodos que antecedem as eleições concentraram o maior número de ações e $60 \%$ dos processos catalogados no serviço aconteceu durante as campanhas eleitorais.

\section{FUNDAMENTAÇÃo LEgAL NO MARCO CIVIL DA INTERNET PARA BLOQUEIO DO WHATSAPP}

O Marco Civil da Internet é a resposta do poder legislativo brasileiro aos conflitos inerentes à sociabilidade humana, surgidos com a disseminação da sociedade da informação (BARRETO JUNIOR, 2013, passim). Foi precedido de outros "amoldamentos": "No que concerne à produção normativa legislativa, evidencia-se a positivação no Direito brasileiro de dois diplomas legais recentes que representam, de maneira emblemática, essa nova 
positivação: Lei 11.419, de 19 de dezembro de 2006, que dispõe sobre a informatização do processo judicial e a Lei 11.900 , de 8 de janeiro de 2009, que prevê a possibilidade de realização de interrogatórios e outros atos processuais por sistema de videoconferência. " (BARRETO JUNIOR, 2013, passim). O Marco Civil expressa a resposta do legislador, entre outros aspectos advindos da convergência digital e da disseminação em escala mundial da internet, para avançar na proteção da privacidade e dos dados pessoais na rede. Destacamos, nas Disposições Preliminares e nos Princípios da lei:

Disposições Preliminares.

Art. 2-A disciplina do uso da internet no Brasil tem como fundamento o respeito à liberdade de expressão, bem como:

(...)

II - os direitos humanos, o desenvolvimento da personalidade e o exercício da cidadania em meios digitais;

Princípios.

Art. 3ํㅡ disciplina do uso da internet no Brasil tem os seguintes princípios: I - garantia da liberdade de expressão, comunicação e manifestação de pensamento, nos termos da Constituição Federal;

II - proteção da privacidade;

III - proteção dos dados pessoais, na forma da lei;

(...)

De plano nas suas disposições preliminares, conforme exposto acima, o Marco Civil reafirma o alinhamento transnacional brasileiro com os direitos humanos e alude à dicotomia entre direitos fundamentais e absolutos, ao assegurar a liberdade de expressão, parametrizada pela proteção da privacidade e dos dados pessoais dos usuários da rede. Faz-se importante tratar dessa dualidade, inerente à sobreposição histórica entre direitos fundamentais e à potencial elevação dessa dicotomia, provocada pela sociedade em rede que pode ser caracterizada como o paradigma atual do desenvolvimento do capitalismo, que supera os antagonismos entre sociedade, economia, cultura e comunicação informática e configura um novo estágio de desenvolvimento do sistema econômico.

Neste aspecto reside o foco do Marco Civil, no que tange aos aspectos tratados neste artigo: transformações que a sociedade da informação provocou na compreensão e no exercício dos denominados direitos fundamentais. Especialmente nos direitos sobre privacidade e intimidade, uma vez que a atuação dos meios de comunicação midiáticos interfere, decisivamente, nos processos de sociabilidade, frente ao exercício da liberdade de expressão. Conforme assinala Florêncio Filho (2014, p.31), em obra publicada sore a Lei 
12.965/2014: “A partir de uma análise preliminar dos incisos I e II (do Marco Civil da Internet, acréscimo nosso) já se percebe uma colisão entre os princípios da liberdade de expressão e proteção da privacidade. Ou seja, qual o limite entre liberdade de expressão e a privacidade da informação? Apenas o caso concreto vai dizer. " (Ibid., p.41)

A repercussão, alcance e potencial de uma ofensa ou calúnia em meio digital atingem velocidade e dimensões inimagináveis, quando propagadas pela internet. Discute-se o direito ao sigilo e ao esquecimento, mas uma informação, imagem ou vídeo divulgados pela rede dificilmente tem seus conteúdos e rastros totalmente suprimidos. Deve-se isso ao potencial multiplicador das redes sociais, tal como Facebook e Twitter, e da disseminação pelas ferramentas de comunicação em tempo real, sendo a mais usual nos dias de hoje o aplicativo WhatsApp.

Além das questões relacionadas à privacidade e à intimidade, imprescindíveis socialmente, várias indagações surgem quando é tratado o bloqueio do WhatsApp, objeto deste artigo. Florêncio Filho (2014, p.40) leciona que "o Marco Civil da Internet, apesar de suas imperfeiçoes, foi um importante passo simbólico para afirmar os direitos e garantias dos usuários da internet e reafirmar as obrigações dos provedores na rede mundial de computadores”. Para tal finalidade, no Capítulo II, dos Direitos e Garantias dos Usuários, o Marco Civil expressa, in verbis:

Art. 7o $\mathrm{O}$ acesso à internet é essencial ao exercício da cidadania, e ao usuário são assegurados os seguintes direitos:

I - inviolabilidade da intimidade e da vida privada, sua proteção e indenização pelo dano material ou moral decorrente de sua violação;

II - inviolabilidade e sigilo do fluxo de suas comunicações pela internet, salvo por ordem judicial, na forma da lei;

III - inviolabilidade e sigilo de suas comunicações privadas armazenadas, salvo por ordem judicial;

(...)

VI - informações claras e completas constantes dos contratos de prestação de serviços, com detalhamento sobre o regime de proteção aos registros de conexão e aos registros de acesso a aplicações de internet, bem como sobre práticas de gerenciamento da rede que possam afetar sua qualidade;

VII - não fornecimento a terceiros de seus dados pessoais, inclusive registros de conexão, e de acesso a aplicações de internet, salvo mediante consentimento livre, expresso e informado ou nas hipóteses previstas em lei;

VIII - informações claras e completas sobre coleta, uso, armazenamento, tratamento e proteção de seus dados pessoais, que somente poderão ser utilizados para finalidades que:

a) justifiquem sua coleta; 
b) não sejam vedadas pela legislação; e

c) estejam especificadas nos contratos de prestação de serviços ou em termos de uso de aplicações de internet;

IX - consentimento expresso sobre coleta, uso, armazenamento e tratamento de dados pessoais, que deverá ocorrer de forma destacada das demais cláusulas contratuais;

$X$ - exclusão definitiva dos dados pessoais que tiver fornecido a determinada aplicação de internet, a seu requerimento, ao término da relação entre as partes, ressalvadas as hipóteses de guarda obrigatória de registros previstas nesta Lei;

Esse conjunto de aspectos do Art. $11^{\circ}$, voltados a proteção e inviolabilidade da privacidade, da intimidade e da vida privada, não asseguraram que milhões de usuários do WhatsApp no Brasil tivessem cerceado seu acesso ao aplicativo, nas decisões propaladas na seção anterior deste artigo. Os magistrados fundamentaram suas decisões nos artigos e incisos transcritos a seguir:

\section{CAPÍTULO III \\ DA PROVISÃO DE CONEXÃO E DE APLICAÇÕES DE INTERNET \\ Seção II}

Da Proteção aos Registros, aos Dados Pessoais e às Comunicações Privadas

Art. 11. Em qualquer operação de coleta, armazenamento, guarda e tratamento de registros, de dados pessoais ou de comunicações por provedores de conexão e de aplicações de internet em que pelo menos um desses atos ocorra em território nacional, deverão ser obrigatoriamente respeitados a legislação brasileira e os direitos à privacidade, à proteção dos dados pessoais e ao sigilo das comunicações privadas e dos registros. (Grifos nossos)

$\S 1$ o $\mathrm{O}$ disposto no caput aplica-se aos dados coletados em território nacional e ao conteúdo das comunicações, desde que pelo menos um dos terminais esteja localizado no Brasil.

$\S 2^{\circ} \mathrm{O}$ disposto no caput aplica-se mesmo que as atividades sejam realizadas por pessoa jurídica sediada no exterior, desde que oferte serviço ao público brasileiro ou pelo menos uma integrante do mesmo grupo econômico possua estabelecimento no Brasil.

§ 3ํ Os provedores de conexão e de aplicações de internet deverão prestar, na forma da regulamentação, informações que permitam a verificação quanto ao cumprimento da legislação brasileira referente à coleta, à guarda, ao armazenamento ou ao tratamento de dados, bem como quanto ao respeito à privacidade e ao sigilo de comunicações. (Grifos nossos)

$$
\text { (...) }
$$

Observa-se no artigo supracitado a vontade do legislador de submeter empresas internacionais de tecnologia, como Google, Facebook e Apple aos domínios da soberania brasileira, na forma do alcance da jurisdição pátria. Foi um dos pontos mais controversos do Marco Civil, não obstante a clara necessidade de sua implementação, que caso não ocorresse 
faria da nova legislação letra morta, imediatamente no seu nascedouro. Ainda quanto ao fundamento dos magistrados para o bloqueio do WhatsApp, destacamos as passagens a seguir:

Art. 12. Sem prejuízo das demais sanções cíveis, criminais ou administrativas, as infrações às normas previstas nos arts. 10 e 11 ficam sujeitas, conforme o caso, às seguintes sanções, aplicadas de forma isolada ou cumulativa:

I - advertência, com indicação de prazo para adoção de medidas corretivas;

II - multa de até $10 \%$ (dez por cento) do faturamento do grupo econômico no Brasil no seu último exercício, excluídos os tributos, considerados a condição econômica do infrator e o princípio da proporcionalidade entre a gravidade da falta e a intensidade da sanção;

III - suspensão temporária das atividades que envolvam os atos previstos no art. 11; ou

IV - proibição de exercício das atividades que envolvam os atos previstos no art. 11.

Parágrafo único. Tratando-se de empresa estrangeira, responde solidariamente pelo pagamento da multa de que trata o caput sua filial, sucursal, escritório ou estabelecimento situado no País.

(Grifos nossos).

Não obstante os efeitos sociais evidentes do bloqueio da ferramenta de mensagens em tempo real, é visível a coerência do ato com o teor do artigo 12. Há previsão tanto da suspensão do serviço, quanto da aplicação da multa. Assertivas semelhantes podem ser identificadas no art. 13, que determina o registro e manutenção dos registros de conexão, sob sigilo e em ambiente controlado, e ainda a possibilidade de disponibilização desses registros ao poder público desde que precedida de solicitação judicial.

\section{Subseção I \\ Da Guarda de Registros de Conexão}

Art. 13. Na provisão de conexão à internet, cabe ao administrador de sistema autônomo respectivo o dever de manter os registros de conexão, sob sigilo, em ambiente controlado e de segurança, pelo prazo de 1 (um) ano, nos termos do regulamento.

§ 5o Em qualquer hipótese, a disponibilização ao requerente dos registros de que trata este artigo deverá ser precedida de autorização judicial, conforme disposto na Seção IV deste Capítulo.

Dessa forma, seria interessante um caminho do meio entre essas visões, permitindo a liberdade, algo tão presente na Internet, onde qualquer um pode ter uma ideia e desenvolvê-la, mas que os controles necessários para que os funcionamentos fossem implementados e principalmente com transparência, pois esse é um mundo que fica oculto aos olhos dos usuários e é de difícil compreensão para muitos, evitando assim abusos. Contudo, esse é um assunto demasiadamente novo, onde complementações ocorrerão, nesse sentido, falta ainda ao 
Marco Civil da Internet a regulamentação prevista para os casos em que a quebra dos paradigmas da privacidade e do sigilo contraponha-se às decisões judiciais. A afirmação supra serviria ainda ao artigo $15^{\circ}$, que trata da Guarda de Registros de Acesso a Aplicações de Internet na Provisão de Aplicações, como se apresenta in verbis, a seguir:

\section{Subseção III \\ Da Guarda de Registros de Acesso a Aplicações de Internet na Provisão de Aplicações}

Art. 15. O provedor de aplicações de internet constituído na forma de pessoa jurídica e que exerça essa atividade de forma organizada, profissionalmente e com fins econômicos deverá manter os respectivos registros de acesso a aplicações de internet, sob sigilo, em ambiente controlado e de segurança, pelo prazo de 6 (seis) meses, nos termos do regulamento.

$\S 1^{\text {o }}$ Ordem judicial poderá obrigar, por tempo certo, os provedores de aplicações de internet que não estão sujeitos ao disposto no caput a guardarem registros de acesso a aplicações de internet, desde que se trate de registros relativos a fatos específicos em período determinado.

$\S 2$ - A autoridade policial ou administrativa ou o Ministério Público poderão requerer cautelarmente a qualquer provedor de aplicações de internet que os registros de acesso a aplicações de internet sejam guardados, inclusive por prazo superior ao previsto no caput, observado o disposto nos $\S \S 3$ e e $4^{\circ}$ do art. 13.

§ 3 Em qualquer hipótese, a disponibilização ao requerente dos registros de que trata este artigo deverá ser precedida de autorização judicial, conforme disposto na Seção IV deste Capítulo.

§ 4을 $\mathrm{Na}$ aplicação de sanções pelo descumprimento ao disposto neste artigo, serão considerados a natureza e a gravidade da infração, os danos dela resultantes, eventual vantagem auferida pelo infrator, as circunstâncias agravantes, os antecedentes do infrator e a reincidência.

Dessa forma, ficam vulneráveis os dados registrados em aplicações de smartphones, uso de programas de localização, padrões de busca no Google ou demais ferramentas, postagens no Facebook, Twitter, Snapchat e Instagram, utilização de ferramentas como Uber e Ifood, aquisição de produtos e serviços pela Internet, ou mesmo a instalação e uso de jogos como a atual coqueluche Pokémon Go. Nada justifica a maneira como esses casos são tratados, violando princípios essenciais a um Estado de direito tal como o sigilo e a privacidade, cabendo aos operadores do direito corrigir tais abusos de forma a se permitir ao poder judiciário autorizar o acesso às informações solicitadas nas investigações criminais, sem sacrificar os direitos fundamentais. 


\section{CONSIDERAÇÕES FINAIS}

Para adequada análise do Marco Civil é imprescindível recorrer às teorias clássicas do pensamento jurídico e sociológico. Norberto Bobbio (2009, p.670), em conceito adequado para a profusão de conflitos inerentes à sociabilidade on-line e a inadaptabilidade dos tradicionais parâmetros normativos para tais situações, assevera que: "o desenvolvimento da técnica, transformação das condições socioeconômicas, a ampliação do conhecimento e a intensificação dos meios de comunicação poderão (...) criar condições para o nascimento de novos carecimentos e novas demandas de liberdade e poderes. " Ainda, para Bobbio (ibid., p.670), "os critérios de eleição e a assimetria entre os direitos fundamentais são extremamente vagos, demasiados vagos para a concretização daquele princípio de certeza de que parece ter necessidade o sistema jurídico para distribuir imparcialmente a razão e a não razão"

Tais avanços trazem novos desafios ao Direito que se depara com novas situações e vem respondendo a elas. Porém, o Direito possui uma velocidade muito mais lenta que as evoluções tecnológicas, então esse mundo digital possui muito a ser juridicamente discutido e trabalhado.

Não será surpresa se o bloqueio do WhatsApp voltar a tornar-se objeto de novas medidas judiciais, não obstante o decreto que regulamenta o Marco Civil da Internet prevê que as teles e os aplicativos não precisarão mais entregar à Justiça dados cadastrais de seus usuários quando não armazenarem esse tipo de informação. Conforme matéria do jornal Folha de São Paulo (06 de maio de 2016), “embora o decreto abra exceção para informações como nome, filiação, endereço, estado civil e profissão, algumas empresas do setor entenderam que isso fortalecerá empresas como o WhatsApp, que teve o serviço bloqueado duas vezes por não entregar dados protegidos de usuários solicitados via judicial. " O jornal destaca que o aplicativo argumenta que não armazena esses dados. Ainda segundo a matéria, “As teles e os apps ficariam obrigados a armazenar dados como IP (registro numérico do computador de acesso à internet) e até os sites navegados pelo usuário. Esse tipo de informação poderia ser entregue a autoridades em casos de investigações criminais. " (Jornal Folha de São Paulo, (06 de maio de 2016)).

Quando se pensa no futuro da Internet, o sigilo dos dados pessoais está inserido em um contexto de preocupação, pois novos serviços surgem e competem com outros aplicativos, 
inclusive do próprio provedor de conexão, e esses aplicativos trafegam cada vez maior quantidade de dados. Dessa forma, a preservação da privacidade e da intimidade viriam se contrapor a possíveis abusos, assegurando assim os direitos fundamentais dos usuários da rede, e que representam os princípios do Marco Civil da Internet.

Os que defendem dizem que esses princípios passam pela ausência de registros ou negativa de pedidos de acesso a dados de aplicação ou de comunicação entre usuários. Os que são contrários trazem como argumento que esses abusos podem ser questionados junto às autoridades judicial. A inobservância dessas diferenças pode colocar em risco princípios basilares da internet como espaço livre e democrático.

\section{REFERÊNCIAS}

BARRETO JUNIOR, Irineu Francisco. Atualidade do Conceito Sociedade da Informação para a pesquisa jurídica. In: PAESANI, Liliana Minardi (coord.). O Direito na Sociedade da Informação. São Paulo: Atlas, 2007.

Abordagens recentes da pesquisa jurídica na Sociedade da Informação. In: PAESANI, Liliana Minardi (coord.). Direito na Sociedade da Informação V. 2. São Paulo: Atlas, 2009.

BARRETO JUNIOR, Irineu Francisco. Aspectos Sociológicos da Lei dos Delitos Informáticos. In: PAESANI, Liliana Minardi (coord.). O Direito na Sociedade da Informação III: a evolução do direito digital. São Paulo: Atlas, 2013.

Proteção da Privacidade e de Dados Pessoais na Internet: O Marco Civil da rede examinado com fundamento nas teorias de Zygmunt Bauman e Manuel Castells.. In: DE LUCCA, Newton; SIMÃO FILHO; Adalberto; DE LIMA; Cintia Rosa Pereira. (Org.). Direito \& Internet III: Marco Civil da Internet. 1ed.São Paulo: Quartier Latin, 2015, v. 2, p. $100-127$.

BOBBIO, Norberto. A Era dos Direitos. 9. ed., Rio de Janeiro: Elsevier, 2009. 
BRASIL. Constituição da República Federativa do Brasil. Disponível em: <http://www.planalto.gov.br/ccivil_03/Constituicao/Constituicao.htm>. Acesso em: 20.03.2016.

BRASIL. Lei 8078/90 (Código de Defesa do Consumidor). Disponível em: <http://www.planalto.gov.br/ccivil_03/leis/L8078.htm>. Acesso em: 20.03.2016.

BRASIL. Lei 12.965 de 23 de abril de 2014 (Marco Civil da Internet). Disponível em: <http://www.planalto.gov.br/ccivil_03/_ato2011-2014/2014/lei/112965.htm> Acesso em: 12.06.2015.

CASTELLS, Manuel. (traduzido por GERHARDT, Klauss Brandini; MAJER, Roneide Venâncio) A Era da Informação: Economia, Sociedade e Cultura. Fim do Milênio. v.3, São Paulo: Paz e Terra, 2012.

GUERRA, Gustavo Rabay. Direito à Inviolabilidade e ao Sigilo das Comunicações Privadas Armazenadas: um grande salto rumo à proteção judicial da privacidade na rede. In: LEITE, George Salomão; LEMOS, Ronaldo (coordenadores). Marco Civil da Internet. São Paulo: Atlas, 2014

JESUS, Damásio de. Marco Civil da Internet: comentários à lei n. 12.965, de 23 de abril de 2014. São Paulo: Saraiva, 2014, p. 17.

KLEE, Antonia Espíndola Longoni; MARTINS, Guilherme Magalhães. A privacidade, a Proteção de Dados e dos Registros Pessoais e a Liberdade de Expressão: Algumas Reflexões sobre o Marco Civil da Internet no Brasil (Lei 12.965/2014). In: DE LUCCA, Newton; SIMÃO FILHO, Adalberto; LIMA, Cíntia Rosa Pereira de (coordenadores). Direito \& Internet III - Tomo I: Marco Civil da Internet (Lei 12.965/2014). São Paulo: Quartier Latin do Brasil, 2015.

LIMA, Caio César Carvalho. Garantia da Privacidade e Dados Pessoais à Luz do Marco Civil da Internet. In: LEITE, George Salomão; LEMOS, Ronaldo (coordenadores). Marco Civil da Internet. São Paulo: Atlas, 2014. 
LIMA, Fernando Gaburri de Souza. A Boa-Fé Objetiva e seus Desdobramentos em Relação ao Dever de Informação dos Provedores de Conexão e Acesso a Aplicações da Internet. In: DE LUCCA, Newton; SIMÃO FILHO, Adalberto; LIMA, Cíntia Rosa Pereira de (coordenadores). Direito \& Internet III - Tomo I: Marco Civil da Internet (Lei 12.965/2014). São Paulo: Quartier Latin do Brasil, 2015.

PEREIRA, Marcelo Cardoso. Direito à Intimidade na Internet. Curitiba: Juruá, 2011.

RODOTÀ, Stefano. (traduzido por: DONEDA, Danilo; MORAES, Maria Celina Bodin) A Vida na Sociedade da Vigilância: A privacidade hoje. Rio de Janeiro: Renovar, 2008. 